Journal of English Language Teaching and Applied Linguistics

ISSN: 2707-756X

DOI: $10.32996 /$ jeltal

Journal Homepage: www.al-kindipublisher.com/index.php/jeltal

JELTAL

\title{
Landscaping the Philippine Languages: The Implementation of Multilingual Education Policy
}

\section{Christian Lawrence N. Reyes}

National University-Baliwag, the Philippines

Corresponding Author: Christian Lawrence N. Reyes, E-mail: cnreyes@nu-baliwag.edu.ph

\author{
ARTICLE INFORMATION \\ Received: August 08, 2021 \\ Accepted: October 08, 2021 \\ Volume: 3 \\ Issue: 11 \\ DOI: $10.32996 /$ jeltal.2021.3.11.1
}

\section{KEYWORDS}

Language policy, MTB-MLE, multilingual education, language program, Philippine languages

\section{ABSTRACT}

The institutionalization of Mother Tongue-Based Multilingual Education (MTB-MLE) in the Philippines through the Department of Education order no. 74. series of 2009 outlining aspirations for a culture-centered mother tongue-based instruction is positioned to focus on the acquisition of language content and allow the learners to experience a theoretically based, well-planned educational program that provides a strong foundation for literacy using the cognitive skills and comprehension of academic content from day one. However, the dynamic process of teaching and learning brought many factors contributing to the implementation of the program as the key language policy of the Philippines. With this, the researcher examined the extent of program implementation through the use of qualitative and quantitative data. The study employed validated and standardized survey instruments and used Statistical Package for the Social Sciences (SPSS) to analyze the gathered data, and it applied descriptive analysis to determine the level or degree of implementation. Also, the perspectives of language teachers were taken into account to ensure a better view of the panorama as they are the end-users. Findings suggested that (1) the policy has been implemented to a great extent by the teachers; teachers have a good grasp of the program. Also, (2) teachers are providing relevant and responsive delivery of instruction in order to capitalize the learner's capability.

Published by Al-Kindi Center for Research and Development, London, United Kingdom. Copyright (c) the author(s). This open access article is distributed under a Creative Commons Attribution (CC-BY) 4.0 license (https://creativecommons.org/licenses/by-nc-nd/4.0/)

\section{Introduction}

The Department of Education (DepEd) issued DepEd Order No. 74, series of 2009 which positioned Mother Tongue-Based MultiLingual Education as the official language policy of the basic education system in the Philippines which aimed to improve the use of the English language of students, together with the vision to resuscitate our geographically-based languages and minority languages. Thus, justice and equality among languages are put into consideration with the aid of MTB-MLE, and learning of concepts in the schools can be acquired by learners easily. It is an aggressive attempt of the Philippines government to underscore learners' capacity to acquire basic concepts through the use of their first language.

Now that there is MTB-MLE in the Philippines, students can easily comprehend lessons and instructions given by their teachers using their first language. The Philippines is considered a language laboratory since it has 168 geographically-based languages and minority languages and others are yet to be reported. It can be viewed as a challenging opportunity for national education administrators in implementing this program because each regional and local language is unique and complex and as it is perceived differently by different language groups in the country especially when it comes to program implementation given that the country is an archipelago and availability of resources may vary from one local to another.

In 1948, the United Nations Declaration of Universal Human Rights affirmed the right to education without discrimination. After that declaration, another milestone has been achieved, in 1953, UNESCO expanded this by endorsing the mother tongue to be used as the medium of instruction. It states that: 
According to UNESCO (1953), it is best for a child to use his first language in learning. It provides systems of meaningful signs relative to how his mind works automatically. In education, he learns through it faster because it is familiar to him.

It is an affirmation that access to education should not be limited to only a few, but for all. Given that this is one of the movements behind the structural and ideological changes in the landscape of language policy in the Philippines, one cannot deny its sustainability and applicability in the countries like the Philippines, since it provides greater opportunities for learners to learn and participate.

Moreover, it is worth noting that it is the Philippines is the only ASEAN country that institutionalized multilingual education as its official language policy in the curriculum (Martin \& Tupas, 2016), through the Department of Education Order 74, series 2009 and later adapted in the Enhanced Basic Education Act of 2013.

For this reason, a program like MTB-MLE is worth revisiting, provided that its implementation is something unique in Southeast Asia, it can be viewed as a benchmark for our neighboring countries, yet we say that it can never run without any problem. Its effectivity has been in various experimental research conducted in the Philippines and in abroad, but it underwent changes and gone through problems over time.

On this note, the challenge always lies on the end-users of the program, the teachers, and through this, the extent of their implementation shall be revisited. Now, this paper sought to determine the extent of program implementation of multilingual education policy and how do teachers implement the program?

\section{Review of Related Literature}

Martin (2008) opined that the English language is the most-feared language in the Philippines. With the current MTB-MLE, students can easily comprehend lessons and instructions. The Philippines is considered a language laboratory since it contained 168 geographically-based languages and minority languages. It can be viewed as a challenging opportunity for national education administrators in implementing this program because each regional and local language is unique and complex and it is perceived differently by different language groups in the country. And one of the many challenges MTB-MLE is facing in the Philippines is it has been continuously receiving counterblows from those who believe that English is and those who speak English are superior, not realizing that this policy would be an agent to intensify our global competitiveness in the face of the world.

Singh, Zhang, and Besmel (2012) argue that a society with access to resources supporting multilingual and multicultural ideals may gain advantages in terms of social and economic roles in this era of globalization. Mother tongue education as a part of multilingual policies has been recognized as part of cultural development. The use of mother tongue language is a compromise to the conflicts emerging between the domination of a language over local languages.

Scholars have also looked into this area of multilingual education and language anxiety and the results of their study may vary depending on the context and localization. Also, its relationship is undeniably evident since both are connected with language learning and development. However, the reservoir of research examining the relationship between language anxiety, proficiency, and multilingualism has been little or scarce (Thompson \& Lee, 2012). And as found out by Bensalem (2018) found out that multilingualism produces a range of anxiety from low to average after engaging college students learning English as a foreign language. This confirms that multilingualism actually has an effect on anxiety.

\subsection{Statement of the Problem}

This paper ought to unravel the perceptions of teachers as end-user of the program, MTB-MLE towards the implementation and its extent. Specifically, the following questions ought to be answered:

1. What is the perception of teachers towards the extent of their implementation of the program?

2. How do teachers implement the program?

3. What implications may be drawn from the findings of the study?

\section{Method}

The provisions of Enclosure No. 1 to the DepEd Order No. 74, s. 2009 known as Fundamental Requirements for a Strong Mother Tongue-Based Multilingual Education (MLE). The researcher to measure the extent of the implementation of multilingual policy. The data collected were tabulated and processed using Statistical Packages for Social Sciences (SPSS). The findings were presented using the necessary tables and figures. In order to analyze and interpret the data gathered, the following statistical measures were used: the extent of the implementation of mother tongue-based multilingual policy by the teacher-respondents 
was quantified using the necessary rating scale, range of scoring, and descriptors. Also, an interview was conducted in order to gain insights from the informants on how they execute the program.

\subsection{Data Gathering Procedure}

The mode of data gathering was the survey questionnaire method. Each of the respondents was given a well-structured, wellinstructed, and standardized set of questions to describe quantitatively, for the teacher-respondents, the extent of implementation of mother tongue-based multilingual education policy.

\section{Results and Discussion}

\subsection{The Extent of the Implementation of Mother Tongue-Based Multilingual Education Policy}

Sound policies are very essential in order to implement educational plans and achieve desired goals in learning the language. In this regard, there is a constant and massive effort to revolutionize the teaching and learning of language, consistent with the demands of the ever-changing world.

In the study of Björklund, Björklund, and Sjöholm (2013), the significance of a minority language as opposed to a dominating language has been emphasized to gain recognition from a number of countries where several indigenous or regional languages serve as barriers to language learning. The use of mother tongue language as an initial step to help learners gain the fundamental principles or knowledge about a second or foreign language is very essential.

Singh, Zhang, and Besmel (2012) argue that a society with access to resources supporting multilingual and multicultural ideals may gain advantages in terms of social and economic role in this era of globalization. Mother tongue education as a part of multilingual policies has been recognized as part of cultural development. The use of mother tongue language is a compromise to the conflicts emerging between the domination of a language over local languages.

In this study, the extent of the implementation of a multilingual education policy was quantified in terms of the perception of respondent-teachers using the guidelines issued by the Department of Education.

\begin{tabular}{|c|c|c|}
\hline Indicators & Mean & Interpretation \\
\hline There is a working orthography (spelling) for the chosen & 5.00 & Very Great Extent \\
\hline \multicolumn{3}{|l|}{ local language. } \\
\hline There are inexpensive instructional materials in the & 5.00 & Very Great Extent \\
\hline \multicolumn{3}{|l|}{ designated language at the school, division, and } \\
\hline \multicolumn{3}{|l|}{ regional levels with a special priority on beginning } \\
\hline \multicolumn{3}{|l|}{ reading and children's literature. } \\
\hline Learner's first language is the medium of instruction from & 5.00 & Very Great Extent \\
\hline \multicolumn{3}{|l|}{ Kinder to Grade 3 in the subjects like Maths, Science, } \\
\hline \multicolumn{3}{|l|}{ Makabayan, Filipino, and English. } \\
\hline Filipino, English, and other local and foreign languages are & 4.00 & Great Extent \\
\hline \multicolumn{3}{|l|}{ introduced as separate subjects in a carefully planned } \\
\hline \multicolumn{3}{|l|}{ pacing program and not earlier than Grade two. } \\
\hline Mother Tongue as a subject and as a medium of instruction & 4.00 & Great Extent \\
\hline \multicolumn{3}{|l|}{ is introduced in Grade one for conceptual understanding. } \\
\hline In the secondary level, Filipino and English shall be & 4.00 & Great Extent \\
\hline \multicolumn{3}{|l|}{ primary medium of instruction (MOI). } \\
\hline The language of instruction is also the primary language & 5.00 & Very Great Extent \\
\hline
\end{tabular}




\begin{tabular}{|l|l|}
\hline of testing. \\
\hline A continuing in-service training (INSET) in partnership \\
\hline with MLE specialist has been implemented. \\
\hline \multicolumn{2}{|l|}{} \\
\hline There is strong support for the program implementation \\
\hline from the local government unit, parents, and community. \\
\hline \\
\hline Ensuring critical awareness, maximum participation, and \\
\hline support from the LGU, parents, and community for the \\
\hline implementation of the language and literacy program \\
\hline strategy. \\
\hline Average Mean & Very Great Extent \\
\hline
\end{tabular}

As can be observed from the data presented in the table above, the mother tongue-based multilingual education policy is implemented to a very great extent by the teacher-respondents as evidenced by the average mean score of 4.64 . The result indicates that the said respondents very satisfactorily complied with the mandate to set in motion a multilingual education policy based on the mother tongue language.

Mother tongue-based multilingual education policy is implemented to a great extent when a working orthography (i.e. spelling) is present for chosen local language (5.00), when expensive instructional materials are available for language education primarily on beginning reading and children's literature at the school, division, and regional levels (5.00), when the learner's first language is used as the medium of instruction from Kinder to Grade 3 in the subjects like Math, Science, Makabayan, Filipino and English (5.00) when the language of instruction utilized is also the primary language of testing (5.00), when critical awareness, maximum participation, and support from the local government unit, parents, and community are ensured for the implementation of the language and literacy program strategy (5.00), when a continuing in-service training (INSET) in partnership with MLE specialist is implemented (4.85), and when the program implementation receives strong support from the local government unit, parents, and community (4.57).

On the other hand, the implementation is said to be to a great extent when Filipino, English, and other local and foreign languages are introduced as separate subjects in a carefully planned pacing program and not earlier than Grade two (4.00), when Mother Tongue as a subject and as a medium of instruction is introduced in Grade one for conceptual understanding (4.00), and when Filipino and English shall be the primary medium of instruction (MOI) in the secondary level (4.00).

$\mathrm{Hu}$ (2015) found the signification of the use of mother tongue in learning a language. The study reasons out that second and foreign language learners of English, as well as their educators, utilize their first languages in order to create a "nurturing environment" for learning. The use of mother tongue in giving instructions, exercises and drills, code-switching, and the likes provide building blocks of fundamental knowledge in order for them to acquire a certain range of competency, which will be useful as they further acquire learning inputs.

Yassin and Razak (2017) revealed that mother tongue-based teaching interferes with the level of anxiety or stress experienced by language learners. The interference was studied considering the years of study of the respondents. The effect of such interference was found more prominent among lower years and less among their counterpart in the higher levels.

\subsection{Program Implementation}

To check the consistency and reliability of data, the researcher included an interview from which he described and analyzed how teachers implement multilingual. These were the results of the interview, as examined by the researcher.

1. As a language teacher, I allow my learners to use their native tongue to ask questions for clarification.

2. Give the learners more speaking activities inside the classroom and group work after class hours.

3. I use multilingual practices by giving them the chance to express themselves without minding grammatical errors. I believe encouraging them to concentrate on communicative success rather than formal accuracy will help them utilized the language and be more comfortable in it. 
4. During discussions, recitations, and other speaking activities, I allow my learners to speak without interfering with them. If there are corrections, I do them after the performance or activity.

5. I make sure that learners feel comfortable during the class; their first language is essential since it will give them the ability to perform at their best.

6. We can lower or lessen the language anxiety of learners by encouraging and giving them positive feedbacks. Always tell them that mistakes are an integral part of learning because there is no perfect beginner.

7. I use materials provided by the Department of Education to ensure that I am on the same page with other teachers.

From the insightful ideas of the teachers, the researcher identified key ideas and points which were combined to form one big idea that serves as synthesis. Based on the answers, the participant-teachers believe that using their native language in the multilingual setting plays an imperative role for the learners because students feel that they can get the chance to ask questions, participate in activities, and find meaning to words they can't understand. Using the first language to translate concepts into a second language helps encourage learners to participate and learn. This is related to code-switching. Also, materials are provided for the teacher's use.

\subsection{Implications Based on the Findings of the Study}

The following are the implications drawn based on the findings of the study:

1. Based on the findings, teachers have expressed a positive attitude and high hopes for the MTB-MLE, as they adapted the program, provided that the government gave them enough support and materials to strengthen the implementation.

2. Practices of the teachers show how they support the program and its applicability in the teaching-learning process. It may also infer that students' participation through the use of MTB-MLE can be maximized, through this, teachers were able to provide ample opportunity for students to participate.

3. The Department of Education and basic learning institutions may use primary strategies and mechanisms to strengthen the program in terms of the availability of teaching and learning materials to further support the program implementation.

\section{Conclusions}

In light of the findings of the study, the following conclusions were drawn:

1. The mother tongue-based multilingual policy is implemented to a very great extent by educators in compliance with the present mandate.

2. A number of implications drawn from the findings of the study may help language educators to consider the continuous implementation of multilingual policies as an aid to language education courses or as a tool for the workplace and globalization demands.

3. Materials and training are provided for teachers to ensure program compliance and to further the implementation.

\section{Recommendations}

Based on the findings and conclusion of the study, the following recommendations are at this moment submitted:

1. Educators are encouraged to continue implementing up-to-date policies consistent with international and local standards in keeping with the goals and objectives of the public and private educational institutions.

2. School administrations are requested to sponsor seminars and programs, which aim to engage teachers, parents, and learners in the continuous development of school policies to multilingual education.

3. Future researchers are encouraged to consistently evaluate the implementation of multilingual education (MTB-MLE).

4. Future researchers are encouraged to explore multilingual education and its impact on Filipino students in the future. 


\section{References}

[1] Bensalem, E. (2018). Multilingualism and foreign language anxiety: The case of Saudi EFL learners. Learning and Teaching in Higher Education: Gulf Perspectives, 15(2).

[2] Björklund, M., Björklund, S.,\& Sjöholm, K. (2013). Multilingual policies and multilingual education in the Nordic countries. International Electronic Journal of Elementary Education, 6(1), 1-22.

[3] $\mathrm{Hu}, \mathrm{C}$. (2015). Mother tongue interference in English language pronunciation of the Chinese immigrant in the United States. Master's Projects and Capstones. 218.

[4] Martin, I.P. (2008). Fearing English in the Philippines. Manila: Philippine Daily Inquirer. Retrieved on October 9, 2011, from http://opinion.inquirer.net/inquireropinion/columns/view/20080412-129893/Fearing-English-in-the-Philippines

[5] Singh, N., Zhang, S., \& Besmel, P. (2012). Globalization and language policies of multilingual societies: Some case studies of South East Asia. RBLA, Belo Horizonte, 12v (2), 349-380.

[6] Thompson, A. S., \& Lee, J. (2012). Anxiety and EFL: Does Multilingualism Matter? International Journal of Bilingual Education and Bilingualism, 16, 730-749

[7] Tupas, R., \& Martin, I. P. (2016). Bilingual and mother tongue-based multilingual education in the Philippines. Springer International Publishing 